\title{
Avaliação da eficácia do software "Alfabetização Fônica" para ALUNOS COM DEFICIÊNCIA MENTAL ${ }^{1}$
}

\author{
A ssessment of efficacy of the Phonic Literacy software for students \\ WITH INTELLECTUAL DISABILITY
}

\author{
Julia Margarida HEIN ${ }^{2}$ \\ Maria Cristina Triguero Veloz TEIXEIRA ${ }^{3}$ \\ Alessandra Gotuzo SEABRA ${ }^{4}$ \\ Elizeu Coutinho de MACEDO 5
}

\begin{abstract}
RESUM O: o objetivo do estudo foi verificar a eficácia da intervenção com o software Alfabetização Fônica Computadorizada em alunos com deficiência mental. O software possibilita a realização de atividades que desenvolvem a consciência fonológica ea compreensão das relações grafofonêmicas. Participaram do estudo 22 crianças eadolescentes com idades entre 10 a 17 anos. Foi feita avaliação inicial do nível intelectual com a Escala de Maturidade Mental Columbia ea Escala deInteligência Weschsler para Crianças. Os participantes foram divididos al eatoriamenteem dois grupos: experimental econtrole. Os grupos foram pareados por sexo, idadee nível de inteligência. A Bateria de A valiação de Leitura e Escrita ea Prova de Consciência Fonológica por Produção Oral foram aplicadas no início etérmino do estudo. Dezesseis sessões individuais com o software "Alfabetização Fônica Computadorizada" foram conduzidas com os participantes do grupo experimental. Os resultados indicaram mel hora nas habilidades deescrita eleitura enos indicadores de consciência fonológica apenas para as crianças eadolescentes do grupo experimental. Comparação com dados normativosidentificaram queos participantes do grupo experimental apresentavam um desempenho semel hanteao decrianças no final do ensino infantil e, após a intervenção o desempenho era semel hanteaqueles da 2 a série do ensino fundamental.
\end{abstract}

PALAVRAS-CHAVE: deficiência mental; leitura; consciência fonológica; tecnologia.

ABSTRACT: the aim of the study was to verify the effectiveness of computer based intervention with the Phonological A wareness Literacy Software for students with intellectual disabilities. The software enables participation in activities that stimulatethe development of phonological awareness and graphemeto phoneme conversion. Twenty-two children and teenagers between theages of 10 and 17 years participated in thestudy. Initial evaluation of cognitive development level was performed using the Columbia Mental Maturity Scale and theWechsler Intelligence Scale for Children. All the participants were randomly divided into two groups:

\footnotetext{
${ }^{1}$ A poio: CN Pq e Mackpesquisa da Universidade Presbiteriana Mackenzie.

${ }^{2}$ Mestre em Distúrbios do Desenvolvimento pela Universidade Mackenzie. Professora da Associação Catarinense de Ensino. juliahein@bol.com.br

${ }^{3}$ Doutora em Filosofia da Saúde pela Universidade Federal de Santa Catarina. Professora dos Programas de Mestrado e Doutorado em Distúrbios do Desenvolvimento da Universidade Presbiteriana Mackenzie, SP. Bolsista PQ do CNPq. cris@teixeira.org

${ }^{4}$ Doutora em Psicologia Experimental pela Universidade de São Paulo. Professora dos Programas de Mestrado e Doutorado em Distúrbios do Desenvolvimento da Universidade Presbiteriana Mackenzie, SP. Bolsista PQ do CNPq. Centro de Ciências Biológicas e da Saúde. alessandra.seabra@mackenzie.br

${ }^{5}$ Doutor em Psicologia Experimental pela Universidade de São Paulo. Professor dos Programas de M estrado e Doutorado em Distúrbios do Desenvolvimento da Universidade Presbiteriana Mackenzie, SP. Bolsista PQ do CNPq. Centro de Ciências Biológicas e da Saúde. elizeumacedo@uol.com.br
} 
experimental and control. Thegroups werematched for sex, age, and cognitivedevelopment level. The Reading and Writing Tests Battery and The Verbal Phonological A wareness Test were used for assessment at the beginning and end of the intervention program. Sixteen individual sessions were run with the experimental group participants using theComputerized Phonological Reading software. Theresults indicated improvements in writing, reading and phonological awareness skills only for the experimental group. Comparison with normativedata showed that beforetheintervention theexperimental group's performancewas on thelevel of pre-school children, but after theintervention, they tested at the $2^{\text {nd }}$ gradelevel.

KEYWO RD S: Intellectual disability; Reading; Phonological A wareness; Technology.

\section{IINTRODUÇÃO}

Conforme o Censo de 2000 , aproximadamente $15 \%$ da população brasileira apresenta al gum tipo de deficiência e, desse total, 68\% têm al gum tipo de deficiência mental (JAN NUZZI , 2004). O Manual Diagnóstico e Estatístico de Transtornos Mentais (ASSOCIAÇÃO AMERICANA DE PSIQUIATRIA, 2003) estabel ece como característica essencial da deficiência mental um funcionamento intelectual significativamente inferior à média, acompanhado de limitações significativas no funcionamento adaptativo em pelo menos duas das seguintes áreas de habilidades: comunicação, autocuidados, vida doméstica, habilidades sociais/ interpessoais, uso de recursos comunitários, autossuficiência, habilidades acadêmicas, trabalho, lazer, saúde e segurança. Os fatores que predispõem às diferentes condições de retardo mental podem ser biológicos, psicossociais ou al guma combinação de ambos. Em aproximadamente 35\% dos indivíduos vistos em contextos clínicos, não é possível determinar uma etiologia específica para a deficiência mental, apesar de extensos esforços de avaliação. Os principais fatores predisponentes incluem: hereditariedade, anormalidades em gene único com herança mendeliana e expressão variável, aberrações cromossômicas, al terações precoces do desenvolvimento embrionário, problemas da gravidez e perinatais, outras condições médicas gerais adquiridas no início da infância e, influências ambientais, dentre outros (ASSOCIAÇÃ O AMERICANA DE PSIQUIATRIA, 2003).

Em 1994 foi assinada a Declaração de Salamanca (BRASIL, 1994), que reafirma o compromisso da educação para todos e reconhece a necessidade de implementar programas de alfabetização eeducação para crianças, jovens eadultos com necessidades educacionais especiais. No Brasil, este processo de inclusão tem sido pautado em leis, decretos e diretrizes nacionais de diferentes ministérios, tais como o Ministério da Justiça, especial mente pela Coordenadoria $\mathrm{N}$ acional para a Integração da Pessoa Portadora de Deficiência - Corde(BRASI L - CORDE, 1997), e o M inistério da Educação, especial mente pelas Secretarias de Educação Especial e de Educação Básica. A inclusão educacional do aluno com deficiência mental é legislada oficial mente pela Lei de Diretrizes eBases da Educação N acional - Lei no 9.394/ 96, no artigo 59 (BRASIL, 1996). 
O desenvolvimento de procedimentos pedagógicos com eficácia comprovada torna-se um desafio para todos aqueles que trabal ham com pessoas que apresentam algum grau de deficiência mental. A informatização de procedimentos e a criação de materiais pedagógicos com recursos tecnológicos podem trazer benefícios para o aprendiz (IDE, 1996; TJUS; HEIMAN N ; NELSON, 2001; LI-TSAN G etal., 2007; STOCK et al., 2008).

A tualmente, o conhecimento produzido pela psicologia cognitiva eas neurociências têm contribuído para o desenvolvimento de novas abordagens de tratamento e atendimento especializado, criando possibilidades de intervenções mais eficazes para o ensino dealunos portadores de deficiência mental . A orientação das secretarias de educação especial é focada em um primeiro momento no conhecimento que o professor deveter das características individuais dos al unos para, em uma segunda etapa, poder elaborar um programa de ensino que objetive superar as limitações. Embora seja esta a recomendação, os professores relatam dificul dades em conduzir o processo deal fabetização a fim de que o al uno ad quira uma leitura fluente e com boa compreensão. Estas dificuldades podem ser explicadas pel o fato de que muitos dos procedimentos usados na al fabetização de discentes com deficiência mental são os mesmos do ensino regular apresentados no Currículo Básico (PA RANÁ, 1994). Defato estudos anteriores têm mostrado o fracasso da inclusão escolar dentro do ensino regular (ENUMO, 2005; GOMES; BA RBOSA , 2006; JURDI; A MIRA LIAN , 2006; LACERDA, 2007; Á VILA, 2008).

Segundo Oliveira (2003), em publicações internacionais importantes, como o N ational Reading Panel Report, o N ational Literacy Strategy e o A pprendre à Lire, quesão documentos estrangei ros formal mente equival entes aos Parâmetros Curriculares $\mathrm{N}$ acional do Brasil, eem artigos mais citados na literatura cientifica internacional, pode-seobservar um consenso entre os cientistas eformuladores de políticas educacionais dos países desenvolvidos a respeito do processo de alfabetização. Assim, ler significa, basicamente, a capacidade de identificar automaticamente as palavras e seus significados, e escrever consisteem transcrever os sons da fala. A mbos envolvem a capacidade de decodificar fonemas em grafemas e vice-versa eainda que podem ser beneficiadas por instruções fônicas explícitas (LEON G, 1991; M CGUINESS, 2004).

Desta forma, o processo de leitura envolveduas habilidades separadas, mas interrelacionadas: reconhecimento de palavra e compreensão. 0 reconhecimento inclui não apenas o domínio da correspondência grafema-fonema e estratégias fônicas, mas também a capacidade de aplicar estas habilidades rapidamentee sem grandes esforços, detal forma que o reconhecimento da pal avra seja feito de forma automática. Dificuldades no reconhecimento automático da pal avra afeta negativamente a fluência de leitura ecompreensão.

A leitura eficiente implica o funcionamento de diversos processos cognitivos, tais como percepção, memória e atenção. À medida que atribui significado ao significante, o processo de reconhecimento das palavras se acelera. 
O sujeito deverá estruturar os elementos lexicais na estrutura sintática, ou seja, deverá atribuir um sentido ao que decodifica, pois além dereconhecer o significado do código éobrigado a reconhecer o sentido desse código e integrá-lo à mensagem como um todo (GARCIA , 1998; CA POVILLA ; CAPOVILLA, 2000a).

De acordo com Frith (1985), podem-se observar três estágios que a criança em processo de alfabetização percorre para adquirir a aquisição da leitura e escrita: logográfico, alfabético e ortográfico. N o estágio logográfico, o leitor trata a palavra escrita como se fosse uma representação pictoideográfica e visual do referente. Nesta fase, a criança faz reconhecimento visual direto com base no contexto, na forma ena cor, mas não atenta às letras, exceto a primeira. N o estágio al fabético com o desenvolvimento da rota fonológica, a criança aprende a fazer decodificação grafofonêmica e passa a ler pseudopal avras e pal avras, desde que sejam regulares grafofonemicamente. Finalmente, no estágio ortográfico desenvolve-se a rota lexical com o domínio do vocabulário do idioma, em quea criança aprende a fazer leitura visual direta de palavras de al ta frequência etornase capaz de ler palavras irregulares desde que sejam comuns.

Ellis (1995) indica queexistem dois caminhos para o leitor conseguir o reconhecimento das palavras e extrair o seu significado: rota fonológica, também chamada de via indireta, erota lexical, conhecida como rota visual ou via direta. A rota fonológica permite a leitura de textos, segmentando-os, por força da metalinguagem, em seus componentes, tais como: parágrafos, períodos, orações, frases, palavras, sílabas ou em sons da fala. Possibilita a identificação dos sons correspondentes a cada uma das letras ou grafemas que compõem a palavra. É uma rota mais lenta já que o processo requerido é muito mais extenso até o reconhecimento da palavra, no entanto, os estágios iniciais da aprendizagem da leitura dependem desta rota. A leitura por essa rota envolve habilidades metalinguísticas, tais como a consciência fonológica. Diversas pesquisas têm mostrado que o processamento fonológico deficitário dificulta a leitura pela rota alfabética, sendo essa uma das principais dificuldades observadas em crianças com problemas de leitura (SHARE, 1995; SA LLES, 2001; SALLES; PARENTE, 2006; ALCOCK et al., 2009; YATES, 2009).

Entende-se por consciência fonológica a habilidade de se refletir sobre a estrutura sonora das palavras faladas, podendo manipular seus componentes (CARVALHO; ALVAREZ, 2000) e a consciência fonêmica como a habilidade específica de se refletir sobre os fonemas. A consciência fonológica envolve a habilidade de analisar a estrutura do som da linguagem falada. Ela inclui a habilidade de segmentar pal avras em seus sons (análise fonêmica) e combinar de volta estes sons em palavras (síntese fonêmica). Estudos recentes sugerem que as abordagens deal fabetização que incorporam treino de consciência fonológica em conjunção com instruções fônicas explícitas devam ser encorajadas (EHRI, 2004)

No Brasil, Capovilla e Capovilla (2000b) enfatizam a importância de instruções fônicas na alfabetização em português. Estudos experimentais com crianças 
com baixo desempenho de leitura mostram que o desenvolvimento da consciência fonol ógica eda habilidade defazer conversão grafofonêmica auxilia nas aquisições de leitura e escrita, do conhecimento de letras, e de outras habilidades do processamento fonológico. Segundo os autores, a introdução de atividades sistemáticas de consciência fonológica durantea al fabetização, associado ao ensino das correspondências grafofonêmicas, têm produzido resultados relevantes para a habilidade de discriminar emanipular os segmentos da fala. No caso particular de crianças com deficiência mental, existem trabal hos que mostram as vantagens do uso de métodos fônicos na aquisição de habilidades deleitura eescrita, assim como no desenvol vimento da consciência fonológica propriamente dita (CONNERS etal ., 2001; CARD; DODD, 2006; HOLM; FARRIER; DODD, 2008; PEETERSet al ., 2008)

O objetivo do presente trabal ho foi identificar possíveis benefícios que alunos com deficiência mental poderiam ter na aquisição de leitura a partir da utilização do software de al fabetização fônica computadorizado (CA POVILLA et al., 2005). O software utiliza um sistema de conversão texto-fala que visa o desenvolvimento de consciência fonológica eo ensino das correspondências letrasom quesão fundamentai s para a aquisição da leitura eescrita. O softwareapresenta uma série de atividades lúdicas e já foi aplicado em estudantes da primeira série do ensino fundamental com dificul dades leves de leitura eescrita, demonstrando resultados animadores (NIKAEDO, 2006).

\section{MÉtodo}

\subsection{Participantes}

Participaram 22 crianças eadolescentes com idades entre 10 e 17 anos $(M=14,04 ; D P=2,15)$ com suspeita de deficiência mental, conforme encaminhamento efetuado por neurologistas, ecapazes de se expressar oralmente. O rebaixamento intelectual foi confirmado por meio da aplicação de dois testes de inteligência, a saber, a Escala deM aturidade Mental Columbia (BURGEMEISTER, 2001) eo Teste de Inteligência Weschsler para Crianças - WISC-III (WESCHSLER, 2002). Conforme dados dos laudos dos neurologistas, as principais etiologias associadas à possível deficiência mental eram Síndrome de Down, Síndrome de West, encefalopatias diversas, Hipoxia Cerebral Perinatal e Meningoencefalite Bacteriana. Os participantes frequentavam tanto o ensino regular, quanto instituições especializadas no estado de Santa Catarina.

\subsection{Instrumentos de AVAliação}

Prova de Reconhecimento de Letras (PNL). A PRL (HEIN , 2006) objetiva aval iar a capacidade de reconhecimento de letras e consiste na apresentação das 25 letras do al fabeto distribuídas em 5 cartões. O testeé aplicado em duas formas, inicialmente com letras bastões e depois com letras cursivas. É apresentado um 
cartão para o participanteeo examinador solicita queeleapontedeterminada letra. São computados os escores, sendo a pontuação máxima de 25 para letra bastão e 25 para letra cursiva.

Prova de N omeação de Letras (PNL). A PNL (HEIN, 2006) consiste na apresentação das 25 letras do alfabeto em forma bastão e cursiva. Cada letra é apresentada isoladamente e criança deve dizer o nome da letra. A ordem de apresentação das letras foi randomizada e o número de letras nomeadas corretamentefoi anotado. O escoremáximo éde 25 pontos para cada tipo deletra, bastão ecursiva.

Teste de N omeação O ral de Figuras (TNOF). O TNOF (CAPOVILLA et al., 2001) é composto pelas figuras casa, el efante, bola e relógio. Cada figura é apresentada em 10 posições diferentes de uma fol ha, distribuídas em uma matriz de 8 colunas verticais e 5 horizontais. A tarefa do aluno é nomear corretamente o mais rápido possível cada uma das figuras, sendo o escore máximo de 40 pontos.

Teste de N omeação de Figuras por Escrita (TNFE). O TNFE (MACEDO et al., 2004) écomposto por 36 figuras em preto ebranco eo aval iando deveescrever o nome de cada figura. As respostas escritas para cada palavra é corrigida como acerto ou erro. Assim, a pontuação máxima é de 36 pontos.

Teste de Competência de Leitura de Palavras e Pseudopalavras (TCLPP). O TCLPP (MACEDO et al., 2004) tem como objetivo avaliar o estágio de desenvolvimento da leitura. O teste é composto por 78 itens, sendo que os 8 itens iniciais são de treino e não entram na pontuação final. Cada um dos itens possui uma figura euma pal avra ou pseudopalavra escrita abaixo. A tarefa do examinando é julgar se a palavra corresponde corretamente ou não à figura. Caso a relação palavra-figura esteja correta, o examinando devefazer um " $C$ "; caso a relação esteja incorreta, devefazer um " $X$ ". Os 70 itens do teste são divididos em sete subtipos de pares figura-pal avra, com 10 itens cada. Os subtipos são: 1) Palavras Corretas Regulares (CR), como a palavra FADA sob a figura deuma fada; 2) Pal avras Corretas Irregulares $(\mathrm{CI})$, como TÁXI sob a figura de um táxi; 3) Palavras com Troca Semântica (TS), como a palavra TREM sob a figura deum ônibus; 4) Pseudopalavras com Trocas Visuais (TV), como a pseudopalavra CABEÇA sob a figura de uma cabeça; 5) Pseudopalavras com Trocas Fonológicas (TF), como a pseudopalavra CANCURU sob a figura de um canguru; 6) Pseudopalavras H omófonas (PH), como pseudopalavra PÁÇARU sob a figura deum pássaro; 7) Pseudopalavras Estranhas (PE), como a pseudopalavra RASSUNO sob a figura de uma mão. A pontuação é de1 ponto para cada acerto. Como existem 70 pares defigura-palavra, a pontuação máxima no teste É de 70 pontos e, em cada um dos sete subtipos de relações, a pontuação máxima é10.

Prova de Consciência Fonológica por Produção Oral (PCF). A PCF (CAPOVILLA; CA POVILLA, 2000b) avalia a habilidade da criança em manipular os sons da fala. É composta de dez subtestes: 1) Síntese Silábica: o participante 
deve unir as sílabas faladas pelo aval iador dizendo qual palavra resulta da união; 2) Síntese Fonêmica: o participante deve unir os fonemas fal ados pelo avaliador dizendo qual palavra resulta da união; 3) Rima: o participante devejulgar dentre três palavras quais são as duas que terminam com o mesmo som; 4) Aliteração: 0 participante devejulgar dentre três palavras quais são as duas que começam com o mesmo som; 5) Segmentação Si lábica: o participante deve separar uma pal avra fal ada pelo aval iador nas duas sílabas componentes; 6) Segmentação Fonêmica: 0 participante deve separar uma palavra falada pelo avaliador nos seus fonemas componentes; 7) Manipulação Silábica: o participante deve adicionar e subtrair sílabas de pal avras dizendo qual a palavra formada; 8) M ani pulação Fonêmica: o participante deve adicionar esubtrai $r$ fonemas de palavras dizendo qual a pal avra formada; 9) Transposição Silábica: o participante deveinverter as sílabas de palavras dizendo qual a palavra formada; 10) Transposição Fonêmica: o participante deve inverter os fonemas de palavras dizendo qual a palavra formada. Cada subteste tem dois itens detreino e 4 deavaliação. A pontuação máxima do testeé 40 pontos e, em cada subteste, 4 pontos.

\subsection{NSTRUMENTO DE INTERVENÇão}

O software Alfabetização Fônica Computadorizada (CA POVILLA etal., 2005) tem como objetivo estimular habilidades deleitura econsciência fonológica. O software éum instrumento interativo queapresenta diversas figuras coloridas e animações com exercícios para estimulação de habilidades de leitura econsciência fonológica. É formado pelos módulos Consciência Fonológica eA Ifabeto.

O módulo Consciência Fonológica possui cinco blocos de atividades: Palavras, Rimas, Aliterações, Sílabas e Fonemas. No bloco "Palavras" são apresentadas frases incompletas e figuras. A criança deve selecionar a figura que melhor completa a frase. Por exemplo, em uma tela aparecem a frase: "Eu comi hoje" e cinco figuras (imã, hipopótamo, lápis, chocolate e jaqueta). O aluno deve escolher, dentre essas cinco figuras, a que melhor completa a frase. A ssim que a figura certa é escol hida, aparece uma animação para exemplificar a frase.

No bloco "Rima", a criança deve selecionar figuras ou palavras que terminam com o mesmo som. Em uma tela, por exemplo, são apresentadas seis figuras (cadeira, geladeira, queijo, mamadeira, pão, mala) eéforneci da a instrução oral para que a criança sel ecione as figuras cujos nomes terminam com / eira/ .

No bloco "Aliteração", o al uno deve selecionar figuras que comecem com o mesmo som. Por exemplo, em uma tela é fornecida a instrução oral para o aluno escolher as figuras que comecem com o som / ca/ , dentreas figuras decasa, cachorro, queijo, sorvete, cavalo e nuvem.

No bloco "Sílabas", a criança inicialmente deve contar o número de sílabas em palavras, classificand o figuras conformeseus nomes sejam monossílabos, dissílabos, trissílabos ou pol issílabos. Posteriormente, são apresentadas à criança 
formas geométricas coloridas em número correspondenteao número desílabas de um nome. A criança deve dizer como fica a palavra retirando ou adicionando sílabas. Por exemplo, em uma tela é dada a instrução oral: “Veja essas formas. O triângulo representa a sílaba/ca/ eo círculo a sílaba/co/ . As duas juntas formam a palavra/ caco/. Seadicionarmos a sílaba/ma/ nafrentede/ caco/, qual palavra formaremos?" A criança deve escolher a figura correta dentreas alternativas uva, violão, avião emacaco.

Já no bloco "Fonemas", são apresentadas formas geométricas coloridas correspondentes ao número de fonemas das pal avras. A criança deve dizer como fica a palavra retirando ou adicionando sons. Em uma tela, por exemplo, é apresentada a instrução oral: “Veja essas formas geométricas. O círculo representa o som / a/ , o retângulo o som / t/ , o círculo o som / a/ . Juntas elas formam / ata/ . Seadicionarmos o som / p/ na frente, qual palavra formaremos". A criança deve selecionar a figura correspondente dentre as alternativas dados, cadeira, pata, fantasma e envelope.

O outro módulo, intitulado Alfabeto, objetiva ensinar as correspondências entre letras e fonemas. Constitui-se pelos blocos "Vogais" e "Consoantes". N o bloco "Vogais", são apresentadas as vogais A, E, I, O e U. N o bloco "Consoantes" são apresentadas as letras F, J, M, N , V , Z, L, S, R, X, B, C, P, D, $\mathrm{T}, \mathrm{G}, \mathrm{Q}$ e H. Em ambos os blocos são apresentadas as letras e os fonemas correspondentes. Há, ainda, atividades em quea criança devesel ecionar figuras e palavras que comecem com a letra-alvo ou com o som da letra-alvo, respectivamente.

\subsection{Procedimento}

Inicialmente os 22 participantes foram avaliados em todos os testes, individual mente, em quatro sessões com duração aproximada de uma hora cada, conduzidas nas próprias instituições. A ordem deaplicação dos testes foi balanceada a fim de evitar efeito de aprendizagem. Após as avaliações do pré-teste, os participantes foram divididos em dois grupos, conforme descrito em resultados. Com o grupo experimental, foram então realizadas 16 sessões de atividades com o software A Ifabetização Fônica Computadorizada (CAPOVILLA et al., 2005). Os partici pantes do grupo controle real izaram atividades em sala de aula e tiveram contato com jogos decomputador quenão estimulavam leitura, escrita econsciência fonológica.

A intervenção com o GE foi realizada individual mente em sessões de aproximadamente 40 minutos de duração e ocorreram duas vezes por semana ao longo de três meses. Durante as intervenções a aplicadora permaneceu ao lado do al uno, observando se estavam engajados na atividade. A aplicadora tinha como função explicar a lição, indicar a sequência das atividades, solicitar a atenção e concentração quando desatento, pedir para quereproduzisse o som de cada letra e 
palavra pronunciada pelo software e registrar o tempo de cada atividade. Como não havia um tempo predeterminado para cada atividade, os participantes variaram com relação ao número total de lições feitas. Cada vez que o al uno completava as 40 atividades do software de computador, iniciava-se outro ciclo até completar as 16 sessões. A sequência de real ização das atividades foi a mesma da sugerida no manual do software, no entanto, como os participantes já haviam demonstrado conhecimento inci piente das consoantes, as atividades de letras foram intercaladas com de consciência fonológica.

A pós o término das 16 sessões, novas avaliações foram conduzidas. Para tanto foram reaplicados todos os testes de leitura, de escrita e de consciência fonológica em todos os 22 participantes.

\section{RESULTADOS E DISCUSSÃo}

\subsection{FormaÇão dos GRUPOS EXPERIMENTAL E CONTROLE}

Para a formação dos grupos experimental e controlea partir da amostra de 22 participantes, foram consi derados os dados de nível intelectual, de leitura e deescrita. Foram consideradas, também, variáveis como idadee sexo. Assim, tanto o GE quanto o GC foram formados por 11 estudantes cada. As pontuações obtidas em todas as aval iações antes da intervenção são apresentadas na Tabela 1. A nova multifatorial foi conduzida a fim de verificar se o GE e o GC apresentavam características semel hantes antes da intervenção. Resultados mostraram não haver diferença significativa na pontuação para nenhuma das habilidades avaliadas.

A medida deinteligência ad otada no estudo foi o QI estimado do WISC. Esta medida foi obtida a partir da pontuação ponderada das provas de Cubos e Vocabulários. A fim de obter os valores finais, foi usada a tabela de estimação do QI indicada em Strauss, Sherman eSpreen (2006). O valor do QI estimado do WISC variou de 62 a 84 efoi usado como covariante para análise do efeito da intervenção nas comparações do pós-teste. O uso do QI estimado como covarianteéimportante para avaliar o efeito da intervenção propriamente dita. Se isto não fosse feito, eventuais ganhos do GE poderiam ser atribuídos às diferenças nos níveis de intel igência entre os participantes dos grupos como apontaram Goswami eBryant (1990). A pontuação bruta na Escala de Maturidade Mental Columbia (EM MC) variou de 27 a 63 pontos.

Embora não tenha sido observada diferença significativa entreo GE eo GC na Prova deN omeação de Letras, ambos os grupos acertaram mais letras do tipo bastão do que letras cursivas na prova de reconhecimento ( $t[19]=4,495 ; p \varangle 0,000$ ) e na denomeação ( $t[19]=9,418 ; p \varangle 0,000$ ). Foi observado, também, queo número letras reconhecidas corretamente foi maior do que o de letras nomeadas, tanto para as cursivas (t[19] =7,628; $p \varangle 0,000$ ), quanto para as letras bastão (t[19]=2,912; $p \varangle 0,009$ ). 
HEIN, J.M.; TEIXEIRA, M.C.T.V.; SEABRA, A.G.; MACEDO, E.C.

Tabela 1 - Valores de media e desvio padrão da avaliação do préteste para o grupo experimental e do controle.

\begin{tabular}{|c|c|c|c|c|c|}
\hline \multicolumn{2}{|l|}{ Idade } & 14,00 & 2,40 & 14,50 & 2,27 \\
\hline \multirow{3}{*}{ Inteligência } & WISC & 70,10 & 7,22 & 70,60 & 9,47 \\
\hline & EMMC - Pont. bruta & 37,50 & 11,58 & 38,90 & 12,74 \\
\hline & EMMC - Pont. ponderada & 44,00 & 8,07 & 47,70 & 11,67 \\
\hline \multirow{2}{*}{$\begin{array}{l}\text { Reconhecimento de } \\
\text { letras }\end{array}$} & Cursivas & 21,10 & 4,53 & 20,30 & 3,37 \\
\hline & Bastão & 24,60 & 0,70 & 22,90 & 3,00 \\
\hline & Cursivas & 15,20 & 4,26 & 14,80 & 5,12 \\
\hline Nomeação de letras & Bastão & 22,60 & 2,41 & 21,30 & 5,10 \\
\hline \multirow[t]{2}{*}{ Nomeação } & Oral & 39,00 & 2,00 & 38,90 & 1,97 \\
\hline & Escrita & 9,35 & 10,21 & 5,43 & 8,73 \\
\hline \multicolumn{2}{|c|}{ Teste de Competência de Leitura de Palavra } & 46,90 & 9,12 & 39,60 & 6,42 \\
\hline & Correta Regular (CR) & 8,10 & 1,85 & 6,60 & 2,59 \\
\hline & Correta Irregular (Cl) & 6,60 & 1,90 & 6,10 & 1,85 \\
\hline & Troca Semântica (TS) & 7,80 & 1,99 & 6,10 & 2,28 \\
\hline & Troca Visual (TV) & 5,10 & 2,51 & 4,70 & 1,95 \\
\hline & Troca Fonológica (TF) & 5,70 & 2,75 & 5,20 & 1,23 \\
\hline & Pseudopalavra Homófona (PH) & 5,40 & 2,22 & 4,50 & 1,96 \\
\hline & Pseudopalavra Estranha (PE) & 8,20 & 2,10 & 6,40 & 1,78 \\
\hline \multicolumn{2}{|c|}{ Prova de Consciência Fonológica } & 17,40 & 8,24 & 15,50 & $\overline{5,52}$ \\
\hline \multicolumn{2}{|c|}{ Rima } & 2,20 & 1,14 & 2,10 & 1,10 \\
\hline & Aliteração & 1,70 & 1,16 & 1,40 & 1,51 \\
\hline & Segmentação Silábica & 2,90 & 1,66 & 3,10 & 1,37 \\
\hline & Síntese Silábica & 3,80 & 0,42 & 3,90 & 0,32 \\
\hline & Manipulação Silábica & 1,60 & 1,35 & 1,10 & 1,29 \\
\hline & Transposição Silábica & 0,70 & 1,34 & 0,00 & 0,00 \\
\hline & Segmentação Fonêmica & 0,70 & 0,95 & 0,40 & 0,97 \\
\hline & Síntese Fonêmica & 2,60 & 1,35 & 2,40 & 0,97 \\
\hline & Manipulação Fonêmica & 0,90 & 0,74 & 0,90 & 1,10 \\
\hline & Transposição Fonêmica & 0,30 & 0,67 & 0,20 & 0,42 \\
\hline
\end{tabular}

Legenda: EMMC - Escala deM aturidadeMental Columbia- WISC - Testedelnteligência Weschsler para Crianças.

A nálise do desempenho no préteste na Prova de Nomeação Oral de Figuras não revelou diferenças entre o GE e o GC sendo que, em ambos, a média de acertos foi próxima da pontuação máxima de 40. A análise dos resultados na Prova de Nomeação de Figuras por Escrita também revelou não haver diferença significativa entreo GE eo GC no préteste. Foi observado que quatro crianças do GE equatro do GC não foram capazes deescrever corretamenteo nomedenenhuma das 36 figuras que faziam parte do teste. Os resultados obtidos revelam baixa capaci dade de nomeação por escrita, sendo que apenas três crianças da amostra total escreveram corretamente o nome de mais de 20 palavras do teste. 
A A nova revel ou, ainda, que o desempenho no Teste de Competência de Leitura dePalavras e Pseudopal avras (TCLPP) também foi semel hanteentreos grupos. A pontuação média obtida pelos dois grupos foi semel hanteà decrianças da $3^{a}$ série do ensino infantil de escolas particulares conforme dados normativos de Macedo et al. (2005). A nálise descritiva dos sete subtipos de pares do TCLPP indicou taxa de acerto acima do acaso para quatro dos sete pares, a saber, $\mathrm{CR}, \mathrm{Cl}$, TSePE. A pontuação foi próxima ao acaso para os pares TV, TF ePH. Tais resultados sugerem que as crianças eadol escentes avaliados tenderam a fazer leitura a partir de um processamento global, com estratégias alfabética e ortográfica de leitura aindaincipientes.

Os resultados do pré-teste mostraram, também, que não houve diferença significativa entre o nível deconsciência fonológica dos dois grupos. De fato, o desempenho na PCF de ambos os grupos foi semelhante ao de crianças da primeira série do ensino fundamental de crianças de escola pública conforme normas deVaranda (2006). A análise dos subitens na PCF identificou dificuldades maiores em itens fonêmicos. A sequência dos cinco itens mais difíceis, em ordem decrescente de dificuldade, foi transposição fonêmica, transposição silábica, segmentação fonêmica, manipulação fonêmica esíntese fonêmica.

Testes de correlação de Pearson foram realizados a fim de identificar as relações entre as habilidades avaliadas no pré-teste, conforme sumariado na Tabela 2. O nível de inteligência avaliado por meio da EMMC correlacionou-se positivamentecom o do WISC-III. A capacidade de escrita avaliada pelo Testede Nomeação de Figuras correlacionou-se positivamente com os dois testes de intel igência ecom a Prova de N omeação de Letras. As correlações mais al tas foram encontradas entrea Prova de $\mathrm{N}$ omeação de Letras com letras cursivas e com letras bastão $(r=0,71 ; p<0,05)$.

Tabela 2 - Coeficientes de correlação de Pearson entre as variáveis do pré-teste: inteligência avaliada pela Escala de Maturidade Mental Columbia (EMMC) e QI estimado no WISC; Reconhecimento de letras cursivas (R_cur) e bastão (R_bas); N omeação deletras cursivas (N_cur) ebastão (N_bas), N omeação por escrita (Ténofe), Teste de competência de leiturā (TCLP) e Provā de Consciência Fonológica (PCF).

\begin{tabular}{|c|c|c|c|c|c|c|c|c|c|}
\hline & EMMC & WISC & cur & as & $\mathrm{N}$ cur & $\mathrm{N}$ bas & Tenofe & TCLP & $\mathrm{CF}$ \\
\hline EMMC & 1,000 & $0,454^{*}$ & $0,504^{*}$ & 0,312 & $0,54 \mathrm{C}$ & 0,314 & $4 \quad 0,653^{\star \star}$ & $\begin{array}{l}* \\
*\end{array}$ & 0,55 \\
\hline WISC & & 1,000 & 0,174 & 0,123 & 0,249 & 0,144 & 0,550 & 0,205 & 0.2 \\
\hline Cl & & & $1,($ & $0,632^{* *}$ & $0,701^{* *}$ & $0,505^{\star}$ & 0,400 & $0 \quad 0,584^{*}$ & * \\
\hline bas & & & & 1,000 & $0,606^{*}$ & $0,727^{\star \star}$ & $0,443^{*}$ & * 0,490 * & * \\
\hline cur & & & & & 1,000 & $0,710^{\star \star}$ & $0,622^{* \star}$ & 0,424 & \\
\hline bas & & & & & & 1,000 & 0,417 & $7 \quad 0,452^{*}$ & * \\
\hline nofe & & & & & & & $1,00 c$ & $0 \quad 0,617^{*}$ & 0,5 \\
\hline CLP & & & & & & & & 1,000 & ) \\
\hline 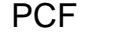 & & & & & & & & & \\
\hline
\end{tabular}

Correl ação é significativa ao nível de 0,05. - **Correlação é significativa ao nível de 0,01. 
Com o objetivo de analisar o efeito da intervenção em consciência fonológica e ensino de correspondências grafofonêmicas, por meio do software de Alfabetização Fônica Computadorizado, foi feita a comparação entre a pontuação obtida no pós-teste e a do pré-teste. Para tanto, foram cal culadas as diferenças entre as duas pontuações, ou seja, pontuação no pós-teste - pontuação no pré teste, de modo a minimizar possíveis diferenças iniciais entre os grupos. Foi conduzida uma Ancova tendo como variáveis dependentes os desempenhos no Teste de Competência de Leitura de Palavras total e nos sete tipos de itens, como fator o grupo (control ee experimental) e como covariante o valor do QI estimado do WISC. A Tabela 3 apresenta valores de média e desvio padrão da diferença da pontuação do pós-teste menos a do pré-teste. Valores negativos indicam que a pontuação no pós-teste foi inferior à obtida no pré-teste.

Em relação aos desempenhos no TCLPP, os resultados apresentados na Tabela 3 revelam que, em termos de média, o número de itens respondidos corretamentefoi maior para o grupo GE, tanto na pontuação total do TCLPP, quanto nos sete tipos de item. Estas diferenças foram significativas $(p<0,05)$ para a pontuação total no TCLPP enos itens TS, TV ePE.

A média deacertos do GE foi de 14,6 pontos a mais no pós-testedo que no pré-teste, enquanto que para o grupo controle praticamente não foi observada variação, com uma diferença de $-0,4$ ponto. Assim, conforme a Ancova, foi observado que o ganho do GE foi significativamente superior ao ganho do GC. Em relação aos tipos de item, embora tenha sido observado aumento na pontuação do GE em todos os subtestes, tal ganho foi significativamente superior ao do GC nos itens com Troca Semântica (3,2 pontos para o GE e 0,5 ponto para o GC), com Troca Visual (2,5 pontos para o GE e 0,2 para o GC enas Pseudopalavras Estranhas (3,1 pontos para o GE e-0,2 para o GC).

Tabela 3- Diferença dos resultados no Teste de Competência de Leitura de Palavras eda Prova de Consciência Fonológica entre o pós-teste e o préteste. Valores de médias das diferenças do pós teste para o pré-teste, com os valores de desvio padrão e das significâncias para os participantes do Grupo Experimental (GE) eGrupo Controle (GC).

\begin{tabular}{|c|c|c|c|c|c|c|}
\hline & \multicolumn{2}{|c|}{$\mathrm{GE}$} & \multicolumn{2}{|c|}{$\mathrm{GC}$} & \multirow[t]{2}{*}{$\mathrm{F}(1,19)$} & \multirow[t]{2}{*}{$\mathrm{p}$} \\
\hline & Média & & Média & DP & & \\
\hline Teste de Competência de Leitura de Palavra & 14,60 & 4,17 & $-0,40$ & 11,47 & 15,103 & 0,001 \\
\hline Correta Regular (CR) & 1,30 & 2,91 & $-0,40$ & 2,37 & & NS \\
\hline Correta Irregular (CI) & 0,70 & 2,21 & $-0,90$ & 2,56 & & NS \\
\hline Troca Semântica (TS) & 3,20 & 2,35 & 0,50 & 1,65 & 8,854 & 0,008 \\
\hline Troca Visual (TV) & 2,50 & 1,90 & 0,20 & 2,66 & 4,954 & 0,039 \\
\hline Troca Fonológica (TF) & 1,70 & 1,89 & 0,70 & 3,71 & & NS \\
\hline Pseudopalavra Homófona $(\mathrm{PH})$ & 2,10 & 3,11 & $-0,30$ & 4,00 & & NS \\
\hline Pseudopalavra Estranha (PE) & 3,10 & 1,45 & $-0,20$ & 1,40 & 26,852 & 0,000 \\
\hline Prova de Consciência Fonológica & 7,50 & 2,80 & 0,10 & 2,13 & 44,241 & 0,000 \\
\hline Rima & 1,40 & 1,07 & $-0,10$ & 0,74 & 13,235 & 0,002 \\
\hline Aliteração & 1,70 & 1,25 & 0,10 & 1,20 & 8,533 & 0,009 \\
\hline Segmentação Silábica & 0,70 & 1,34 & 0,20 & 0,79 & & NS \\
\hline Síntese Silábica & 0,00 & 0,00 & 0,10 & 0,32 & & NS \\
\hline Manipulação Silábica & 1,40 & 0,84 & 0,10 & 0,32 & 20,839 & 0,000 \\
\hline Transposição Silábica & 0,50 & 0,71 & 0,00 & 0,00 & & NS \\
\hline Segmentação Fonêmica & 0,20 & 0,63 & $-0,20$ & 0,42 & & NS \\
\hline Síntese Fonêmica & 0,50 & 0,53 & $-0,10$ & 0,32 & 9,529 & 0,006 \\
\hline Manipulação Fonêmica & 0,90 & 0,99 & 0,00 & 0,67 & 5,651 & 0,029 \\
\hline Transposição Fonêmica & 0,20 & 0,63 & 0,00 & 0,00 & & NS \\
\hline
\end{tabular}

Legenda: NS - Diferenças entremédias estatisticamente não significativas. 
Quando se compara os resultados do Grupo Experimental com os de dados normativos obtidos por Macedo et al. (2005) com crianças de escola regular, os ganhos na pontuação total equivaleriam a quase dois anos de escolarização. Ou seja, a pontuação total no TCLP obtida pelos participantes do GE no pré-teste $(39,6)$ é equivalentea crianças ainda no ensino infantil. No entanto, a pontuação no pósteste $(61,50)$ do mesmo GE é bastante semel hanteàquel as de crianças da segunda sériedo ensino fundamental. Tal evolução podeser explicada pel o fato das crianças passarem a acertar aqueles subitens que tradicional mente são os mais fáceis, tais como as pseudopalavras estranhas etrocas semânticas.

Além da comparação de médias entre os grupos experimental e controle, foi feita uma análise descritiva dos desempenhos individuais de cada participante. A Tabela 4 sumariza tais resultados, em termos de escore no póstestesubtraindo o escore no pré-teste, para cada um dos partici pantes. Em relação ao escoreno TCLPP, observou-se que, no grupo experimental, o maior ganho entre prée pós-avaliação foi de 19 pontos, aumento esseobservado em dois participantes, eo menor ganho foi de 8 pontos. Por outro lado, no grupo controleo maior ganho foi de 22 pontos, eo pior desempenho foi de-24 pontos. Evidenciou-seque houve maior variabilidadeno grupo controlee, apesar de um participanteter obtido ganho expressivo, quatro participantes apresentaram pouco ganho e metade deles apresentou decréscimo na pontuação do pré para o pós-teste. Para o grupo experimental, nenhum participante apresentou decréscimo, sendo que os ganhos variaram entre 8 e 19 pontos. Em relação aos subtestes, um padrão semel hante pode ser observado, com uma tendência a maiores ganhos nos participantes do grupo experimental.

Tabela 4 - Diferença no desempenho entre pré e pós-teste, para cada participante dos grupos controle (C) eexperimental (E), para TCLPP ePCF, em termos deescores totais eem cada subteste.

\begin{tabular}{|c|c|c|c|c|c|c|c|c|c|c|c|c|c|c|c|c|c|c|c|}
\hline & \multicolumn{8}{|c|}{ TCLPP } & \multicolumn{11}{|c|}{$\mathrm{PCF}$} \\
\hline & Tot & $\mathrm{CR}$ & $\mathrm{Cl}$ & TS & TF & $\mathrm{PH}$ & TV & $\mathrm{PE}$ & Tot & $\overline{\mathrm{SiS}}$ & $\mathrm{SiF}$ & $\operatorname{Rim}$ & Alit & SeS & $\mathrm{SeF}$ & $\mathrm{MaS}$ & $\mathrm{MaF}$ & $\mathrm{TrS}$ & TrF \\
\hline \multicolumn{20}{|l|}{$\overline{\mathrm{GC}}$} \\
\hline S1 & -24 & -3 & -4 & -3 & -4 & -4 & -4 & -2 & -5 & 0 & 0 & -2 & -3 & 2 & -1 & 0 & -1 & 0 & 0 \\
\hline S2 & -5 & 1 & -2 & 0 & -2 & -2 & 0 & 0 & 2 & 0 & 0 & 1 & 1 & 0 & 0 & 0 & 0 & 0 & 0 \\
\hline S3 & -5 & 4 & 4 & 0 & -3 & -4 & -3 & -3 & 2 & 1 & 0 & 0 & 0 & 4 & 0 & 0 & 0 & 0 & 0 \\
\hline S4 & -3 & 0 & -2 & 0 & 0 & -3 & 2 & 0 & -2 & 0 & -1 & 0 & 0 & -1 & 0 & 0 & 0 & 0 & 0 \\
\hline S5 & -2 & 0 & 1 & 0 & 0 & -3 & 0 & 0 & 1 & 0 & 0 & 0 & 0 & 0 & 0 & 0 & 1 & 0 & 0 \\
\hline S6 & 1 & -1 & -2 & 0 & 3 & 2 & -1 & 0 & 0 & 0 & 0 & 0 & 0 & 0 & -1 & 1 & 0 & 0 & 0 \\
\hline S7 & 2 & -4 & -3 & 2 & 3 & 1 & 2 & 1 & 1 & 0 & 0 & 0 & 0 & 0 & 0 & 0 & 1 & 0 & 0 \\
\hline S8 & 3 & -1 & 2 & 1 & 0 & -1 & 2 & 0 & 0 & 0 & 0 & 0 & 1 & 0 & 0 & 0 & -1 & 0 & 0 \\
\hline S9 & 7 & 2 & 0 & 3 & 1 & 2 & -1 & 0 & 1 & 0 & 0 & 0 & 1 & 0 & 0 & 0 & 0 & 0 & 0 \\
\hline $\mathrm{S} 10$ & 22 & -2 & -3 & 2 & 9 & 9 & 5 & 2 & 1 & 0 & 0 & 0 & 1 & 0 & 0 & 0 & 0 & 0 & 0 \\
\hline \multicolumn{20}{|l|}{$\overline{\mathrm{GE}}$} \\
\hline $\mathrm{S} 11$ & 8 & 4 & 0 & 2 & 0 & -2 & 1 & 3 & 8 & 0 & 1 & 1 & 2 & 0 & 0 & 2 & 1 & 1 & 0 \\
\hline $\mathrm{S} 12$ & 9 & -2 & -1 & 2 & 2 & 2 & 4 & 2 & 13 & 0 & 0 & 4 & 4 & 4 & 0 & 0 & 1 & 0 & 0 \\
\hline $\mathrm{S} 13$ & 10 & -3 & -3 & 0 & 3 & 4 & 7 & 2 & 6 & 0 & 1 & 1 & 1 & 1 & 0 & 1 & 0 & 1 & 0 \\
\hline $\mathrm{S} 14$ & 14 & 4 & 4 & 2 & 0 & -1 & 1 & 4 & 6 & 0 & 0 & 2 & 1 & 0 & 0 & 2 & 1 & 0 & 0 \\
\hline S15 & 16 & 4 & 0 & 5 & -1 & 3 & 1 & 4 & 9 & 0 & 1 & 1 & 3 & 0 & 0 & 2 & 2 & 0 & 0 \\
\hline $\mathrm{S} 16$ & 16 & -1 & -1 & 4 & 4 & 3 & 3 & 4 & 5 & 0 & 1 & 1 & 2 & 0 & 0 & 2 & -1 & 0 & 0 \\
\hline S17 & 17 & -1 & 0 & 7 & 2 & 4 & 1 & 4 & 7 & 0 & 1 & 2 & 0 & 0 & 0 & 2 & 2 & 0 & 0 \\
\hline S18 & 18 & 5 & 3 & 5 & 1 & -2 & 3 & 3 & 8 & 0 & 0 & 1 & 2 & 2 & 0 & 2 & 0 & 1 & 0 \\
\hline $\mathrm{S} 19$ & 19 & 2 & 2 & 5 & 1 & 2 & 2 & 5 & 3 & 0 & 0 & 0 & 0 & 0 & 0 & 1 & 2 & 0 & 0 \\
\hline S20 & 19 & 1 & 3 & 0 & 5 & 8 & 2 & 0 & 10 & 0 & 0 & 1 & 2 & 0 & 2 & 0 & 1 & 2 & 2 \\
\hline
\end{tabular}


Análise dos resultados da PCF mostrou que os participantes do GC praticamentemantiveram a mesma taxa deacerto no préeno pós-teste para escore total e em todos os subitens da prova. Já o GE apresentou aumento de 7,5 pontos no escore total da PCF do pré para o pós-teste. Foi conduzida uma Ancova a fim de verificar se houve diferença entre o grupo experimental e o controle no ganho de pontuação do pré para o pós-teste. Para tanto, foram cal culadas as diferenças entre as duas pontuações, ou seja, pontuação no pós-teste - pontuação no préteste. A Ancova teve como variáveis dependentes os desempenhos na Prova de Consciência Fonológica total e nos dez subtestes, como fator o grupo (controlee experimental) e como covariante o valor do QI estimado do WISC.

Conformea Tabela 3, os resultados revelaram que os participantes do grupo experimental apresentaram ganho significativamente maior do que os do controle. Os maiores aumentos para o GE foram observados nos subtestes: Manipulação Silábica, Rima, SínteseFonêmica, A literação eM anipulação Fonêmica. Repare-se que, com exceção do subteste de Manipulação Fonêmica, as cinco habilidades restantes em que foram observados ganhos significativos são suprafonêmicas e podem ser adquiridas antes mesmo do início da al fabetização. Porém, embora os partici pantes já estivessem frequentando há al guns anos escolas regulares ou instituições especial izadas, parecem não ter ainda desenvolvido tais habilidades necessárias para uma leitura fluentee o completo domínio da conversão grafema-fonema (OLIVEIRA, 2003).

A análise descritiva dos desempenhos individuais decada participante encontra-se na Tabela 4. Em relação ao escore na PCF, observou-se que, no grupo experimental, o mai or ganho entre prée pós-aval iação foi de 13 pontos, e o menor ganho foi de 3 pontos. Por outro lado, no grupo controle o maior ganho foi de 2 pontos, e o pior desempenho foi de -5 pontos. Pode-se, portanto, observar que o maior ganho no grupo controlefoi inferior ao menor ganho no grupo experimental. Além disso, enquanto todos os participantes do grupo experimental apresentaram aumentos no escore na PCF, no grupo controle dois participantes apresentaram estabilidade e dois apresentaram decréscimo no desempenho. Em relação aos subtestes, um padrão semel hantepodeser observado, com uma tendência a maiores ganhos nos participantes do grupo experimental.

Em suma, os resultados na Prova de Consciência Fonológica eno Teste deCompetência de Leitura dePalavras sugerem queo procedimento deintervenção para desenvolver a consciência fonológica e ensinar as correspondências grafofonêmicas foi eficaz em melhorar os desempenhos em tarefas deconsciência fonológica e leitura de palavras. Além disso, foi observado que o grupo experimental teve o maior aumento da testagem préintervenção para a pósintervenção. Tais diferenças foram significativas em termos de diferenças demédias entre os grupos e também puderam ser observadas em rel ação aos desempenhos individuais dos participantes, apesar da variabilidade intra-grupos. Ou seja, a intervenção com o software foi bastante eficaz em produzir maiores aumentos no desempenho do grupo experimental do queaquel es observados no grupo controle, 
atribuíveis apenas à aprendizagem escolar. Tais resultados coincidem com estudos anteriores (CA POVILLA; CA POVILLA, 2000a; CONNERS et al., 2001; CARD; DODD, 2006; HOLM; FA RRIER; DODD, 2008; PEETERS et al ., 2008). No geral, os dados encontrados indicam que o uso desse software é viável com crianças e adolescentes com deficiência mental.

\section{CONCLUSÃo}

O uso de procedimentos para o desenvolvimento de habilidades metafonológicas e ensino de correspondências grafofonêmicas tem se mostrado eficaz para a aquisição deleitura eescrita, por exemplo, em pré-escolares (PESTUN, 2004) eescolares de baixa renda (CA POVILLA; CA POVILLA, 2000a). O presente estudo mostrou que o uso de procedimentos computadorizados podem também desenvolver habilidades como a consciência fonológica ea leitura de palavras em crianças com deficiência mental $A$ intervenção em consciência fonológica produziu ganhos que foram estatisticamente significativos nos subtestes A literação, Rima, Manipulação Silábica, Manipulação Fonêmica e M anipulação Silábica. O estudo usando o softw are A Ifabetização Fônica Computadorizada mostrou queas crianças do grupo experimental desenvolveram habilidades de consciência fonológica e correspondências letra-som, o que, possivelmente, repercutiu em ganhos significativos na decodificação grafofonêmica. Valesalientar queestes ganhos foram relevantes principalmente para a rota fonológica, devido ao caráter fônico da intervenção. Assim, observou-se que o desenvolvimento dessa rota, com decodificação e conversão degrafemas em fonemas, pode ser um ponto de partida essencial para a alfabetização de crianças com deficiência mental. O software, além das vantagens obtidas no desempenho nas tar efas citadas, apresentou ainda outros benefícios de tipo lúdico, interativo e dinâmico, corroborando a possi bilidade de seu uso com essas crianças.

\section{REFERÊNCIAS}

ALCOCK, K. J. et al. We don't havelanguage at our house: disentangling the relationship between phonological awareness, schooling, and literacy. British Journal of Educational Psychology, London, v. 11, 2009. No prelo.

ASSOCIAÇÃO AMERICANA DE PSIQUIATRIA. M anual diagnóstico e estatístico dos transtornos mentais. Porto A legre: Artes Médicas, 2003.

AVILA, L. A. Grupos e exclusão escolar: os nós que amarram a inclusão e os laços que a envolvem. Paidéia, Ribei rão Preto v. 18, n. 40, p. 399-400, 2008.

BRASIL. D eclaração de Salamanca e linha de ação: sobre necessidades educativas especiais. Brasília: CORDE, 1994.

BRASIL. Ministério da Educação. Lei deDiretrizese Bases da Educação Nacional, LDB Lei № 9.394, de 20 de dezembro de 1996. 
HEIN, J.M.; TEIXEIRA, M.C.T.V.; SEABRA, A.G.; MACEDO, E.C.

BRASIL. CORDE. Capacitação de recursos humanos do ensino fundamental - D eficiência M ental. Brasília DF: Autor. Coordenadoria N acional para a Integração da Pessoa Portadora de Deficiência, 1997.

BRASIL. Secretaria de Educação Especial. D eficiência M ental. D eficiência Física. Secretaria de Educação Especial à D istância, (C adernos da TV Escola). Brasília: Ministério da Educação edo Desporto, 1998.

BRASIL. Secretaria de Educação Especial. Política nacional de edu cação especial na perspectiva da educação inclusiva. Brasília: Ministério da Educação e do Desporto, 2008.

BURGEMEISTER, B. B. Escala deM aturidadeM ental Columbia. São Paulo: Casa do Psicólogo, 2001.

CA POVILLA, A. G. S.; CA POVILLA, F. C. Efeitos do treino de consciência fonológica em crianças com baixo nível sócio-econômico. Psicologia, R eflexão e Crítica, Porto Alegre, v. 13, n. 1, p. 7-24, 2000a.

Problemas de leitura e escrita: como identificar, prevenir e remediar numa abordagem fônica. São Paulo: Memnon, 2000b.

CAPOVILLA, A. et al. A daptação brasileira do International Dysl exiaTest: perfil cognitivo de crianças com escrita pobre. Temas sobre D esenvol vimento, São Paulo, v. 10, p. 30-37, 2001.

CAPOVILLA. F. C. et al. A Ifabetização fônica computadorizada[CD-Rom]. São Paulo: Memnon, 2005.

CARD, R.; DODD, B. The phonological awareness abilities of children with cerebral palsy who do not speak. A ugmentative and A Iternative Communication. Toronto, v. 22, n. 3, p. 149159, 2006.

CA RVALHO, I. A. M.; ALVAREZ, R. M. A. A quisição da linguagem escrita: aspectos da consciência fonológica. Fonoaudiologia A tual, São Paulo, v. 1, n. 11, p. 28-31, 2000.

CON NERS, F. A . etal. A bilities underlying decoding differences in children with intellectual disability. Journal of Intellectual D isabilities Research, London, v. 45, n. Pt 4, p. 292-9, 2001.

EHRI, L. Teaching phonemic awareness and phonics. In: MCCARDLE, P; CHHABRA, V. The V oice of Evidence in R eading R esearch. Baltimore: Brookes Publishing, 2004. p. 153-186.

ELLIS, A. W. Leitura, escrita e dislexia: uma análise cognitiva. Porto A legre: Artes Médicas, 2a edição. Traduzido por Batista, D, 1995.

ENUMO, S. R. F. A valiação assistida para crianças com necessidades educacionais especiais: um recurso auxiliar na inclusão escolar. R evista Brasileira de Educação Especial, Marília, v. 11, n.3, p.335-354, 2005.

FRITH, U.. Beneath the surface of developmental dyslexia. In: PATTERSON, K.; MARSHALL.; COLTHEART, M. (Eds.). Surface dyslexia: neuropsychological and cognitive studies of phon ological reading. London: Erlbaum, 1985. p. 301-330.

GARCIA, J. N. M anual de dificuldades de aprendizagem: linguagem, leitura, escrita e matemática. Porto Alegre: Artes Médicas, 1998.

GOMES, C.; BA RBOSA , A. J. G. Inclusão escolar do portador deparalisia cerebral: atitudes de professores do ensino fundamental. R evista Brasil leira deE du cação Especial , Marília, v. 12, n. 1, p.85-100, 2006. 
GOSWAMI, U.; BRYANT, P. Phonological skills and learning to read. East Sussex, UK: Lawrence Erlbaum, 1990.

HEIN, J. M. Leitura e consciência fon ológica na deficiência mental: intervenções com o programa Alfabetização Fônica Computadorizada. 2006. 84f. Dissertação (M estrado em Distúrbios do Desenvolvimento) - Universidade Presbiteriana Mackenzie, São Paulo, 2006.

HOLM , A.;FARRIER, F.; DODD, B. Phonological awareness, reading accuracy and spelling ability of children with inconsistent phonological disorder. International J ournal of $L$ anguage and Communication D isorders. London, v. 43, n. 3, p. 300-322, 2008.

IDE, S. M. O jogo e o fracasso escolar. In: KISHIM OTO, T. M (Org.). Jogo, brinquedo, brincadeira e educação. São Paulo: Cortez, 1996. p. 88-107.

JANNUZZI, G. A educação do deficiente no Brasil dos primórdios ao início do século XXI. Campinas: Autores Associados, 2004.

JURDI, A. P. S.; AMIRALIAN, M. L. T. M. A inclusão escolar de alunos com deficiência mental: uma proposta deintervenção do terapeuta ocupacional no cotidiano escolar. Estudos de Psicologia. Campinas, v. 23, n. 2, p.191-202, 2006.

LACERDA, C. B. F. O que dizem/ sentem alunos participantes de uma experiência de inclusão escolar com aluno surdo. Revista Brasileira de Educação Especial , Marília, v. 13, n.2, p.257-280, 2007.

LEONG, C. K. From phonemic awareness to phonological processing to language access in children developing reading proficiency. In: SAWYER, D.J.; FOX, B.J. Phonol ogical awareness in reading: the evolution of current perspectives. New York: Springer-Verlag, 1991. p. 217-254.

LI-TSANG, C. W. et al. A 6-month follow-up of the effects of an information and communication technology (ICT) training programme on people with intellectual disabilities. Research in Developmental D isabilities, Illinois, v. 28, n. 6, p. 559-566, 2007.

MACEDO, E. C. et al. D evelopment of a Test Battery to A ssess D eaf Language Skills via www. Web \& M edia - Institute Of Electrical And Engineers IEEE, USA, 2004. p. 118-124.

MACEDO, E. C. et al. Teleavaliação da habilidade de leitura no Ensino Infantil e Fundamental. Psicologia Escolar eE ducacional, Campinas, v 9, n. 1, p. 127-134, 2005.

MCGUINESS, D. Early reading instruction: what science really tells us about how to teach reading. Cambridge, MA: MIT Press, 2004.

NIKAEDO, C. C. Interven ção col etiva com o programa A Ifabetização Fônica Computadorizada em escolares do ensino fundamental. 2006. 97f. Dissertação (M estrado em Distúrbios do Desenvolvimento) - Universidade Presbiteriana M ackenzie, São Paulo, 2006.

OLIVEIRA, J. B. A. A BC do A lfabetizador. Belo Horizonte: A lfa Educativa, 2003.

PARANÁ. Secretaria de Estado da Educação. Fundamentos teórico-metodológicos para a educação especial. Curitiba: Departamento deEducação Especial, 1994.

PEETERS, M. et al. Foundations of phonological awareness in preschool children with cerebral palsy: theimpact of intell ectual disability. Journal of Intell lectual D isabilities R esearch. London, v. 52, n. Pt 1, p. 68-78, 2008.

PESTUN, M. S. V. Investigação precoce da consciência fonológica e futura habilidade de leitura e escrita. Temas sobre D esenvolvimento, São Paulo, v.13, n. 73, p. 5-12, 2004. 
SALLES, J. F. O uso das rotas de leitura fonológica e lexical em escolares: relações com compreensão, tempo de leitura e consciência fonológica. Dissertação (M estrado em Psicologia do Desenvolvimento) - UniversidadeFederal do Rio Grandedo Sul, Porto A legre, 2001.

SALLES, J. F.; PA RENTE, M. A. Funções neuropsicológicas em crianças com dificuldades de leitura e escrita. Psicologia:T eoria e Pesquisa, Brasília, v. 22, n. 2, p. 153-162, 2006.

SHARE, D. Phonological recoding and self-teaching: Sine qua non of reading acquisition. Cognition, v. 55, n. 2, p. 151-218, 1995.

STRAUSS, E.; SHERMAN, E. M. S.; SPREEN, O. A compendium of neuropsychological tests: administration, norms and commentary. N ew York: Oxford University Press. 3rd ed, 2006.

STOCK, S. E. et al. Evaluation of cognitively accessible software to increase independent access to cell phone technol ogy for people with intellectual disability. Journal of Intel lectual D isabilities Research, v. 52, n. 12, p. 1155-1164, 2008.

TJUS, T.; HEIMAN N , M.; NELSON, K. E. Interaction patterns between children and their teachers when using a specificmultimedia and communication strategy: observations from children with autism and mixed intellectual disabilities. A utism.London, v. 5, n. 2, p. 175187, 2001.

WESCHLER, D. WISC-III: Escala deInteligência W echsler para Crianças. adaptação epadronização de uma amostra brasileira. São Paulo: Casa do Psicólogo, 2002.

YATES, M. Phonological neighborhood spread facilitates lexical decisions. Q uarterly Journal of Experimental Psychology, London, v. 62, n. 7, p. 1304-1314, 2009.

Recebido: 30/ 06/ 2009

Reformulado: 14/ 12/2009

A provado: 12/ 02/2010 